\title{
PENERAPAN MOTIF GUNUNGAN DI DAERAH ISTIMEWA YOGYAKARTA
}

\author{
oleh: Suwarna \\ Fakultas Bahasa dan Seni UNY
}

\begin{abstract}
This report taken from research is aim to knowing and describing to apply the motif of gunungan that developed and exploited to various importance: stage, device, logo, decoration, monument and souvenir in Daerah Istimewa Yogyakarta (DIY).

The motif of gunungan is applying in DIY gave attention to: Wayang Ukur Yogyakarta, town device of Yogyakarta, Unwama, Yogya Berhati Nyaman logo, Sleman Sembada, Kulonprogo Binangun, the mosque of Agung Manunggal decoration, Sendang Ayu Sleman monument, BPR Kallyana Adhikamandhana Gunungkidul, and Kotagede silver souvenir. The motif of gunungan, (in the other hand is called: Pohon Hayat, Kalpataru, Kekayon) in the principle of the basic form of isosceles triangle contain the philosophies - symbolic meaning of the only God, still remain to not having change of its external form. The various motifs developed in so many importance as according to its function, so that created various kind of creative motif, but without leave its characteristic, as according to function and its importance. Thus, indicate that the common society, academician, governmental that is appreciative and listen carefully to august values which consisted in the gunungan, it very deep in life utilize to reach the justice and all walks of life welfare. This august values socialization, needed to Pbe child - grandchild not blind to grandmother ommission - great grandparents that is adiluhung, histories.
\end{abstract}

Key words: gunungan = Pohon Hayat, Kalpataru, and Kekayon.

\section{A. Pendahuluan}

Gunungan telah lama dikenal oleh nenek moyang bangsa Indonesia, khususnya oleh masyarakat Jawa dalam pentas Wayang Kulit Purwa. Pementasan wayang ini sampai sekarang masih tetap berlangsung di kalangan masyarakat, bahkan secara rutin stasiun televisi Indosiar hampir setiap Minggu malam menayangkannya, begitu pula TVRI. Hal itu menunjukkan bahwa nilai apresiasi masyarakat cukup tinggi. Wayang mengandung nilai-nilai luhur budaya bangsa yang adiluhung, yang patut dilestarikan sebagai tontonan dan tuntunan. Di dalam pentas wayang, gunungan cukup memegang peranan penting, seperti diungkapkan oleh Van der Hoop (1950: 280): "Dalam permainan bayang-bayang Jawa, yaitu permainan Wajang Kulit, ditaruh di muka tabir (kelir) sebelum dan sesudah permainan, dan juga di antara babakan, suatu benda menyerupai kipas,... berasal dari Jawa Tengah. Benda ini disebut gunungan (sebetulnya pegunungan), disebut

Penerapan Motif Gunungan di Daerah Istimewa Yogyakarta (Suwarna) 
juga kekayon,...gunungan ini melambangkan jumlah kesatuan, keesaan. Oleh karena itu, sama dengan Pohon Hayat." Hal itu banyak mengilhami masyarakat di dalam penciptaan berbagai macam bentuk benda sesuai dengan kepentingannya, di antaranya untuk pentas, lambang, logo, hiasan, monumen, dan suvenir. Dengan demikian, masalah tersebut cukup menarik untuk dikaji.

Tulisan ini bertujuan mendeskripsikan berbagai macam penerapan motif gunungan yang telah dikembangkan dan dimanfaatkan oleh masyarakat di DIY untuk berbagai kepentingan: pentas, lambang, logo, hiasan, monumen, dan suvenir, yang berwujud dua dan tiga dimensional. Nilai-nilai luhur di dalamnya cukup bermakna di hati sanubari masyarakat pendukungnya.

\section{Kajian Teoritik}

Pada masa kebudayaan Hindu di Indonesia, sekitar abad IV s.d. XV Masehi, terutama di Jawa, khususnya di DIY, pengaruhnya sangat terasa. Hal itu dapat dilihat pada kosmologi Hindu bahwa gunung Mahameru merupakan kayangan tempat bersemayamnya para dewa agama Hindu di India. Manifestasinya berupa karya seni rupa yang cukup megah berupa candi-candi dan ter-ejawantahkan lagi ke dalam bentuk gunungan wayang kulit zaman Madya.

Di candi Prambanan terdapat "motif Prambanan". Motif ini sangat terkenal, bentuknya relief simetris, terpadu harmonis, artistik, dan fantastik, terdiri atas tiga bidang. Pada bidang tengah terdapat singa jantan dalam ceruk di bawah anteviks berujung 5, diapit oleh 2 bidang yang berisi 1 pasang pohon Hayat. Masing-masing pohon Hayat diapit oleh kinara-kinari (makhluk Kayangan berkepala manusia dan berbadan burung). Di atas pohon Hayat terdapat payung (cattra) yang diapit oleh sepasang burung. Pohon Hayat dari motif Prambanan ini sangat berpengaruh terhadap kehidupan masyarakat Jawa, merupakan cikal bakal dari motif gunungan yang berkembang dewasa ini (Moertjipto dan Prasetyo, 1992: 68-69). Gambar berikut sebagai contoh.

Setelah agama Islam masuk di Indonesia, juga dihasilkan spesifikasi kebudayaan, salah satunya dapat dilihat di keraton Yogyakarta. Di keraton Yogyakarta terdapat upacara tradisional berujud Garebeg Sekaten. Terdapat lima gunungan sebagai perangkat utama dalam upacara tersebut, yakni: gunungan Lanang, Wadon, Gepak, Dharat, dan Pawuhan. Upacara ini diadakan untuk memperingati kelahiran Nabi Muhammad SAW, setiap 12 Rabiul Awal tahun Hijrah. Fungsi utamanya adalah media dakwah Islam. Gunungan Garebeg dibuat dari hasil bumi, sayur-mayur, dan berbagai kue tradisional. 


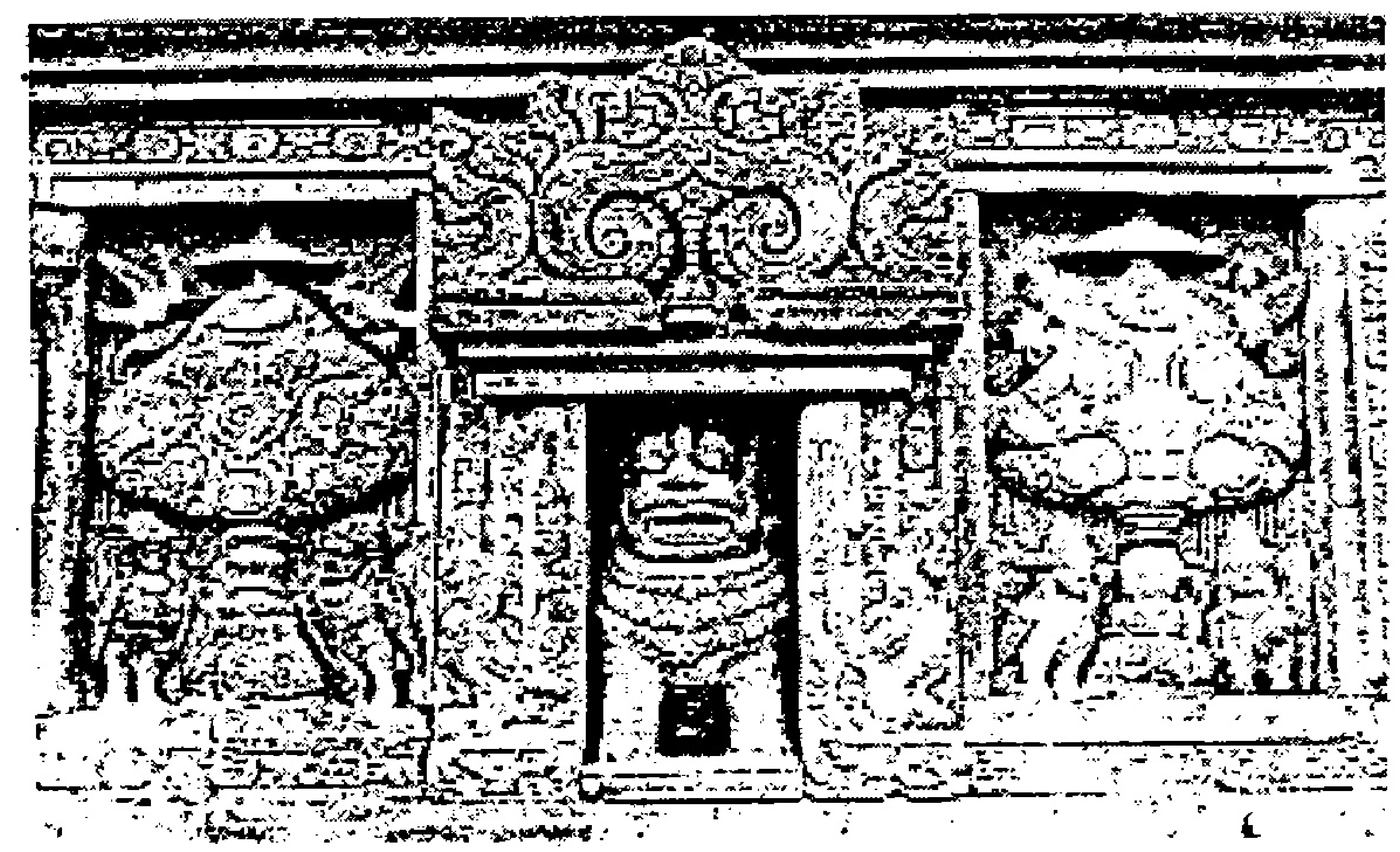

Gambar 1. Motif Prambanan

(Moertjipto dan Prasetyo, 1992: 66)

Kelima gunungan tersebut masing-masing mengandung nilai-nilai simbolis-filosofis. Gunungan berbentuk kerucut melambangkan sorga dan wadhah berbentuk persegi melambangkan bumi. Gunungan Wadon mengandung makna simbolis bahwa seorang ibu rumah tangga berkewajiban menjaga keharmonisan hubungan antara bapak, ibu, dan anak agar kelak roh mereka dapat naik ke surga tanpa rintangan. Gunungan Dharat mengandung makna simbolis orang jangan mudah terpengaruh isu, hasutan, dan fitnah yang dapat mengganggu ketenteraman hidup. Sedangkan khususnya gunungan Gepak berupa kue-kue tradisional dan buah-buahan yang diperuntukkan para petugas, tidak diarak ke halaman masjid Agung Yogyakarta. Gunungan ini ditutup kain bangun tulak untuk menolak segala mara bahaya dan rintangan yang ada di bumi sehingga selamat dapat masuk surga. Gunungan Pawuhan sebagai rangkaian suatu kesatuan yang mengukuhkan hajad dalem dalam wujud sesaji yang telah disucikan merupakan sarana untuk menjaga keselarasan, merupakan siklus lahir-hidup-mati, siang-malam, laki-lakiperempuan, dan siklus alam yang berulang.

Warna dari kue-kue dan sayur-mayur yang dipakai untuk membuat gunungan Garebeg mengandung makna simbolis sebagai berikut. Warna hitam: lambang keabadian, luhur, kekuasaan, keteguhan hati, dan cita-cita. Putih: lambang kesucian, kehidupan, dan kebijaksanaan. Hijau: lambang pengharapan, kesuburan, keselarasan, dan ketenangan. Merah: lambang keberanian dan keuletan. Kuning: lambang kemuliaan, kewibawaan, dan kebesaran (Sunaryo, 1997: 156-175). 


\section{Metode Penelitian}

Penelitian ini menggunakan pendekatan kualitatif. Metode penelitian yang digunakan adalah Desain Studi Medan Ganda, induksi analitik. Pendekatan, pengumpulan, dan analisis data sekaligus sebagai suatu cara untuk membangun suatu teori.

Tujuh ciri penelitian kualitatif seperti dikemukakan oleh Moleong. (1995:4-8): latar alamiah, manusia sebagai alat (instrumen), metode, jenis data diorganisasi dengan klasifikasi subjek, deskriptif, adanya kriteria khusus untuk keabsahan data, desain bersifat sementara (dapat berubah sesuai dengan fenomena yang muncul di lapangan). Pengumpulan data dilakukan dengan teknik observasi, interviu, dan dokumentasi.

\section{Penerapan Motif Gunungan pada Pentas}

Ciptowardoyo dalam 'Wayang sebagai Media Pendidikan Ditinjau dari Arti, Makna, dan Filosofinya' (1985: 25) menyatakan bahwa di dalam kosmologi Hindu secara makrokosmos gunungan diputar-putar di dalam pentas wayang kulit untuk melambangkan proses percampuran benda-benda menjadi satu, terwujudlah kemudian alam beserta isinya. Hal itu disebut "Panca Maha Bhuta" yang melambangkan lima unsur manusia: banu, bani, bayu, banyu, bantala (mikrokosmos). Mikrokosmos dan makrokosmos harus seimbang. Gunungan berhenti diputar berarti dunia diam, wayang dihidangkan, makhluk mulai hidup. Gambar gunungan adalah sebagai berikut.

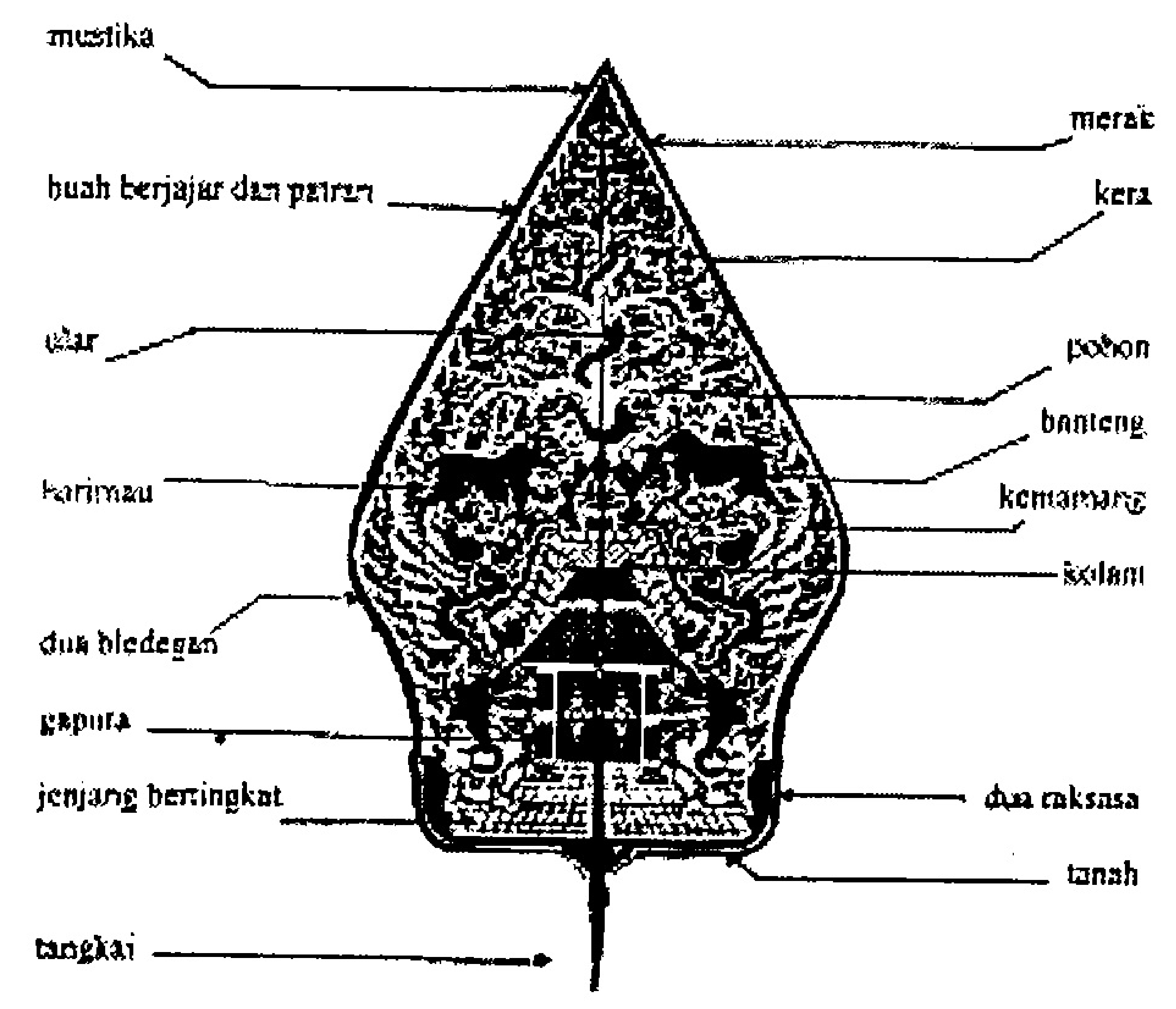

Gambar 2. Gunungan Wayang Kulit Yogyakarta (Ki Mas Bekel Cermo Sutejo dari Banguntapan Bantul)

Imaji, Vol.2, No.2, Agustus 2004 : 265 - 282 
Secara visual Amidjojo (1964: 203-206) menjelaskan motif gunungan sebagai berikut. Kekayon atau gunungan merupakan "pusat pakeliran", bentuk gunungan merupakan segitiga sama kaki, stilirisasi dari bentuk gunung Mahameru, isi utamanya adalah bentuk pohon dan bukit. Dilacak dari namanya, gunungan juga berarti gegunungan atau tetunggul yang berarti paling utama atau paling kuat. Hal itu juga berarti sebagai pikukuhing jagad, sangat relevan dengan isi kandungan Al Quran surat An Nabaa, ayat 7 (1971: 1014) yang maknanya: "dan gunung-gunung sebagai pasak", untuk memperkokoh benua dan pulau-pulau di bumi supaya kuat, tidak bergeser dari posisinya.

Makna simbolis-filosofis dari berbagai motif pada gunungan sebagai berikut.

1. 'Tanah', disebut juga lemahan, merupakan lambang empat unsur manusia, yakni bumi, geni, banyu, angin. Manusia pertama yang diciptakan Allah SWT, Nabi Adam As., dibuat dari tanah. Keempat unsur ini merupakan satu kesatuan yang membuat manusia dapat hidup.

2. 'Pintu gerbang dengan jenjang bertingkat' melambangkan pintu masuk dari alam fana ke alam baka, berpisahnya roh dan raga. Sedangkan jenjang bertingkat melambangkan jalan penuntun agar manusia menaati tuntunan Allah SWT yang berupa ajaran agama Islam.

3. 'Dua raksasa penjaga pintu gerbang', disebut Kala dan Anukala, melambangkan malaikat Munkar dan Nakir yang akan menanyai mayat di dalam kubur tentang siapa Tuhanmu, siapa Nabimu, apa kitabmu. Jika dijawab dengan benar, malaikat akan mengucapkan selamat, dan jika tidak bisa menjawab, maka mayat akan disiksa dan dihina.

4. 'Air di kolam', merupakan tirta amerta, air kehidupan, yang di dalam Mahabarata merupakan minuman khusus para dewa, pengadukan samudera air susu yang melambangkan kemakmuran. Air juga melambangkan darah yang membuat manusia bisa hidup.

5. 'Bledhegan', berjumlah dua buah, melambangkan nafas manusia, begitu juga sebagai lambang dunia atas keperkasaan.

Banaspati atau Kirtimuka disebut juga Kemamang, melambangkan api dan sebagai penguasa hutan, dapat juga diartikan sebagai matahari yang sedang terbit mengintai dari alam gaib tempat roh leluhur bersemayam. Secara filosofis dapat diartikan sebagai ksatria yang berjuang ke arah kesempurnaan hidup.

6. 'Pohon dan permata', disebut pohon Nagasari/Kalpawreksa/Parijatha, pohon Surga. Di dalam Weda disebut Pauh Janggi, memberi ketidakmatian, sebagai sumber kehidupan segala makhluk. Di puncaknya terdapat permata sebagai mustika, mengandung makna bahwa kehidupan manusia hendaknya lurus dengan tujuan mendekatkan diri kepada Tuhan Allah SWT, 
sebagaimana yang dicantumkan di dalam Al Quran Surah Al Fatihah: ihdinashiratal mustaqim, tunjukkanlah kami ke jalan yang lurus. Banyak orang yang menginginkan permata itu mengandung makna karep atau kehendak, berarti mempunyai kehendak hidup yang baik.

7. 'Harimau dan banteng', harimau melambangkan sifat kebuasan manusia, dengan menguasai segalanya untuk menindas yang lain. Banteng melambangkan kekuatan manusia yang kadang-kadang muncul sebagai kesombongan, cepat marah, dan membabi buta, tidak memperhitungkan untung ruginya. Hal itu merupakan godaan. Apabila manusia dapat mengatasinya, maka ia akan mendapatkan mutiara hidup, surga di akherat
nanti.

8. 'Ular', melambangkan budi manusia yang mulia, tahan lapar, gemar bertapa, sabar ketika menemui kesulitan, cerdik, cekatan, tidak suka mendahului dengan perbuatan yang tidak terpuji. Jika diganggu, ia dengan
cekatan membalasnya.

9. 'Burung dan kera', burung senang berkicau melambangkan hiburan atau kenikmatan duniawi dan ketentuan. Jika manusia terlena karenanya, maka akan bisa lupa ibadahnya. Kera melambangkan kejahilan, karena manusia sering nyuk-nyukan, kurang susila. Hal ini juga merupakan peringatan kepada manusia agar mencari bekal hidup kelak di akherat, jangan jahil seperti kera (Amidjaja, 1964: 203-226).

Adapun penerapan motif gunungan dalam pentas wayang kulit adalah: 1) tanda mulai dan berakhirnya suatu permainan, 2) dekorasi panggung: sebagai pohon, hutan, istana, gerbang, api, air, angin, posisi menyesuaikan, 3) gunungan berdiri tegak merupakan tanda gara-gara, punakawan keluar, 4) berganti adegan, bila posisi miring ke kiri berganti adegan sebelum gara-gara, dan jika gunungan miring ke kanan berganti adegan setelah gara-gara (Sastroamidjojo, 1964: 222).

Sigit Sukasman yang beralamat di Mergangsan Kidul MG II/1308 Yogyakarta adalah senirupawan yang berjasa dalam pengembangan wayang kulit purwa. Wayang-nya disebut wayang ukur karena pembuatannya diukur-ukur dengan mistar. Di dalamnya juga terdapat motif gunungan yang diberi nama (oleh penulis karena Sukasman tidak pernah memberinya nama) gunungan wayang ukur $1,2,3,4$. Adapun bentuk gunungan wayang ukur 1 sebagai berikut. 


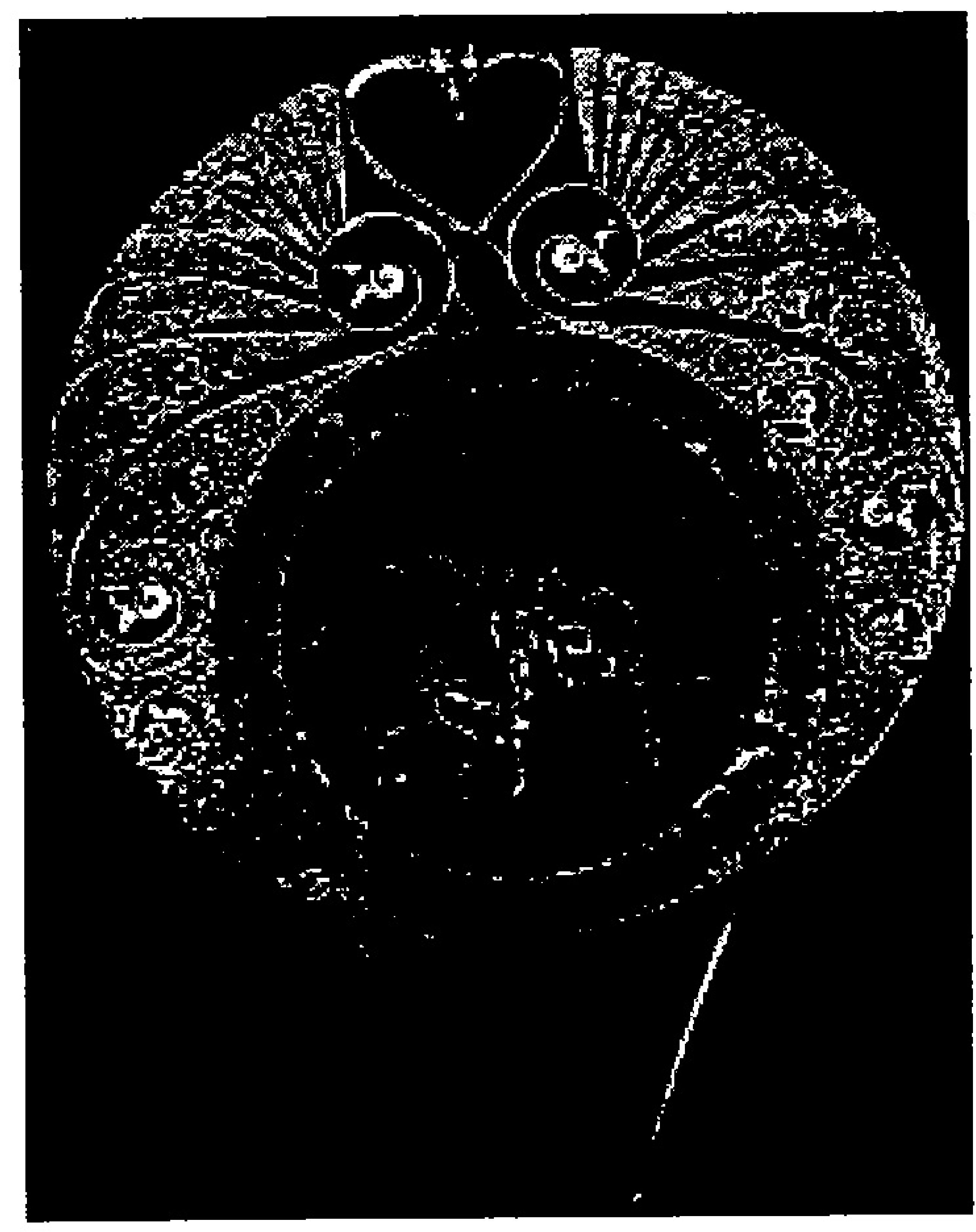

\section{Gambar 3. Gunungan Wayang Ukur1}

Dari keempat gunungan wayang ukur tersebut bentuk gunungan wayang ukur 1 sangat menarik karena berbentuk lingkaran. Sedangkan gunungan wayang ukur yang lain masih terikat dengan bentuk segi tiga sama kaki, seperti lazimnya gunungan wayang kulit purwa. Pada gunungan wayang ukur 1 motif yang muncul adalah sepasang merak yang berhadapan, kedua lehernya berlilitan membentuk ikatan. Kepalanya bertemu pada bagian atas yang membentuk jantung hati, lambang ikatan cinta kasih dan perkawinan. Pertemuan kedua kepala merak ini membentuk bunga kanthil. Bunga kanthil sebagai bunga sakral terdapat juga pada gunungan Lanang Keraton Yogyakarta. Hal itu merupakan lambang kekanthilan atas sepasang pengantin agar mendapatkan rejeki yang halalan thoyiban.

Ekor dan sayap gunungan terkesan menyatu, merupakan evolusi dari garis lurus ke garis melengkung, melambangkan bersatunya antara penguasa dan rakyat: "manunggaling kawula lan gusti". Hal itu merupakan falsafah Keraton Yogyakarta di dalam usaha menjalankan pemerintahan guna kemakmuran dan keadilan rakyatnya.

Motif bola dunia dengan dasar gradasi hijau melambangkan kesuburan jiwa manusia maupun kesuburan bumi yang dapat menumbuhkan berbagai macam tanaman yang sangat bermanfaat bagi kehidupan manusia, guna beribadah kepada Allah SWT. Warna yang muncul, kuning emas, pada motif tumbuhan 
melambangkan keluhuran budi manusia seperti halnya makna simbolis pada gunungan Pawuhan pada upacara Garebeg Karaton Yogyakarta.

Gunungan wayang ukur 2, 3,4 masih tampak bentuk segitiga sama kaki. Hal itu melambangkan keesaan Tuhan dan keteguhan hati. Jika ditinjau secara semiotika, itu merupakan pertanda posisi yang sangat kuat, sebagaimana fungsi gunung-gunung sebagai pasak bumi, merupakan pikukuhing jagad raya. Motif pohon yang lurus masih dipertahankan sebagaimana yang diungkapkan oleh Stutterheim dalam Sastroamidjojo (1964: 217) bahwa kekayon adalah lambang gunung Mahameru, merupakan kayangan tempat bersemayamnya para dewa yang terletak di India bagian utara. Syiwa sebagai Mahadewa yang menjelma sebagai burung Merak Emas yang bersemayam di bukit dinyatakan sebagai sumber hidup
dan penghidupan.

Pada gunungan wayang ukur 4 tẹrdapat bentuk lingkaran di tengah-tengah gapura. Lingkaran itu juga terdapat pada gunungan Lanang upacara Garebeg . Karaton Yogyakarta, sebagai lambang surga yang penuh dengan kesempurnaan.

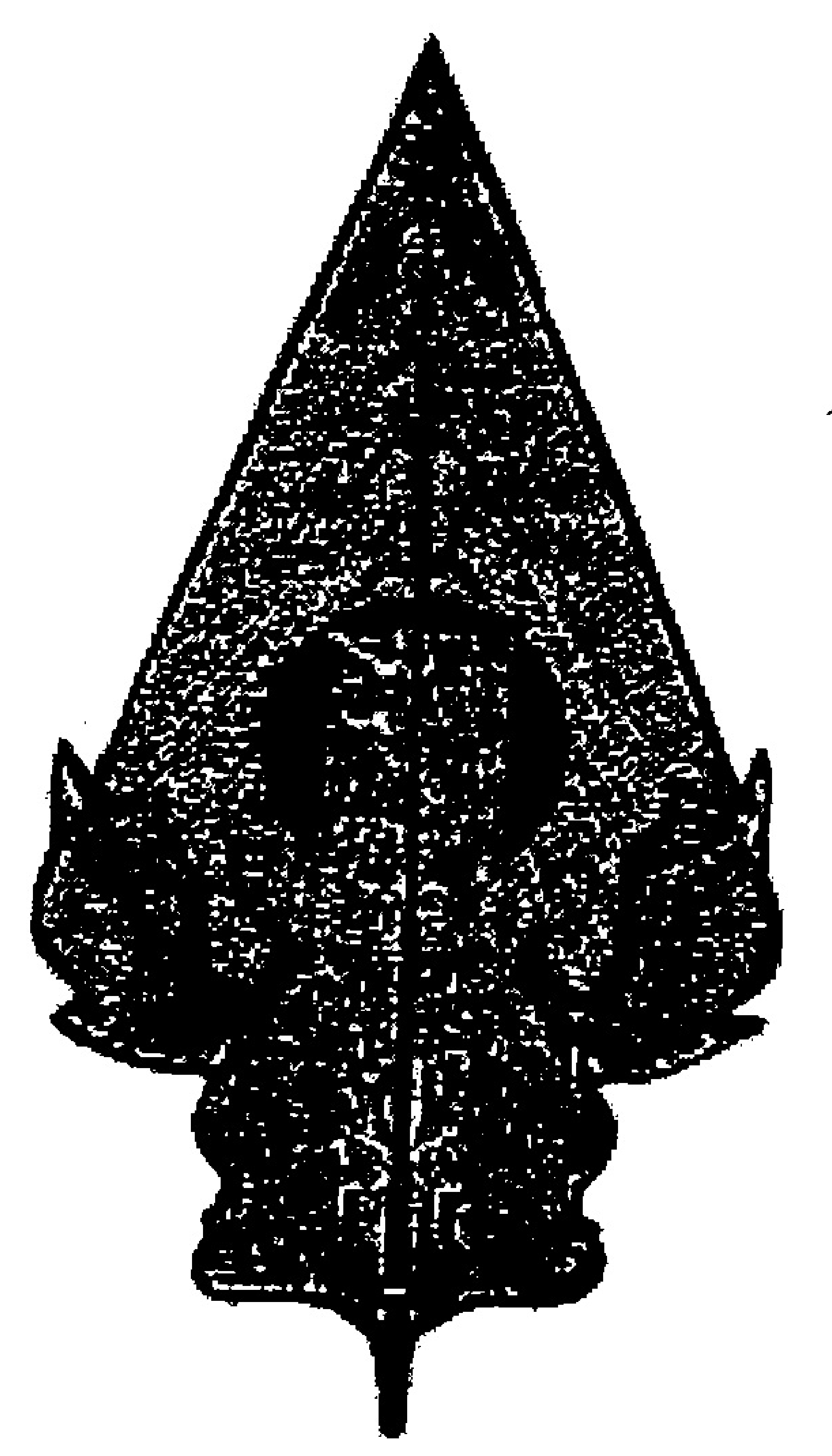

Gambar 4. Gunungan Wayang Ukur 4 


\section{B. Penerapan motif gunungan pada lambang}

\section{Lambang Kota Yogyakarta}

Lambang kota Yogyakarta mengandung motif gunungan tepat di tengahtengah bidang. Di dalamnya terdapat motif pohon beringin kurung yang merupakan lambang kerakyatan. Hal itu telah dicanangkan oleh Sri Sultan Hamengku Buwana IX dalam semboyan "tahta untuk rakyat". Sebagai khalifah di dunia ia sangat memikirkan kemakmuran dan keadilan rakyatnya.

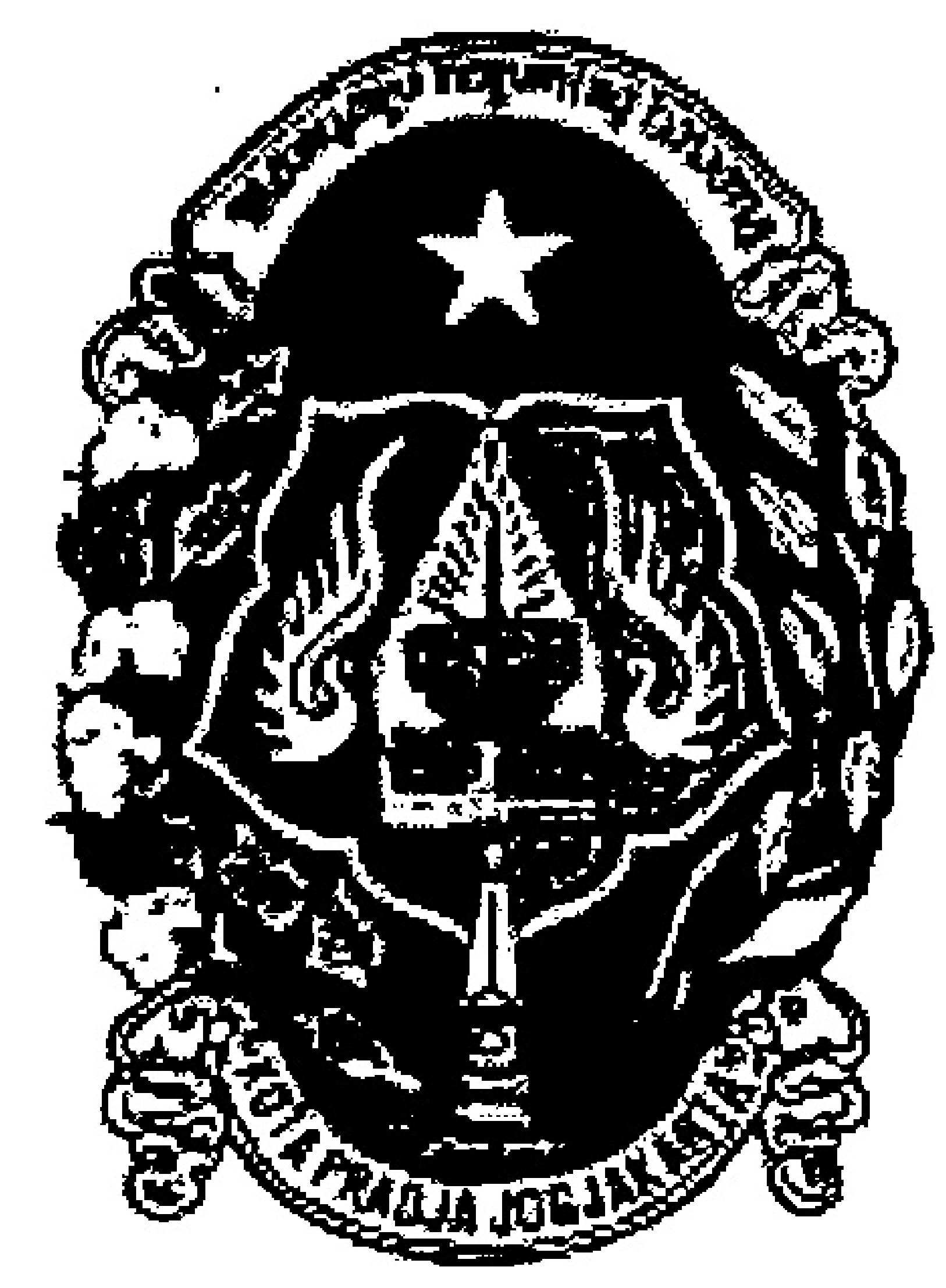

Gambar 5. Lambang Kota Yogyakarta

Banteng lambang semangat keberanian, berani karena benar sebagaimana makna simbolis yang terkandung pada warna merah-putih bendera Indonesia. Merah lambang keberanian, putih lambang kesucian dan kebenaran, maknanya kita berani karena suci dan benar.

Sudah tidak asing lagi bahwa Yogyakarta sebagai kota perjuangan, pelajar, pariwisata, dan budaya. Sesungguhnya, motif gunungan ini melambangkan kebudayaan. Di tengah-tengah motif gunungan terdapat motif keris yang merupakan sengkala memet "gunaning keris anggatra kutha praja", yang kalau dibaca dari belakang berarti tahun 1953 Masehi, tahun mulai dipakainya lambang tersebut. Bila ditinjau secara semiotika, motif gunungan sangat berperan sebagai pengikat berbagai motif, menunjukkan suatu eksistensi dari kota Yogyakarta. Motif gunungan ini berwarna kuning emas, demikian pula halnya motif gunungan pada lambang Universitas Wangsa Manggala (UNWAMA) Yogyakarta atau lambang Kabupataen Kulon Progo. Warna kuning emas mengandung makna simbolisfilosofis: keluhuran, kewibawaan, kemuliaan, dan kebesaran, sebagaimana warna kuning pada unsur gunungan upacara Garebeg Keraton Yogyakarta. Dengan demikian, kesamaan persepsi atas warna kuning emas dan nilai-nilai yang terkandung di dalam motif gunungan telah menyatu di hati sanubari generasi penerusnya yang siap melestarikannya.

Penerapan Motif Gunungan di Daerah Istimewa Yogyakarta (Suwama) 


\section{Lambang UNWAMA}

Lambang UNWAMA secara global berbentuk segi lima beraturan, di dalamnya terdapat motif padi dan kapas, gunungan, buku, dan semboyan "Angudi mulyaning bangsa". Sedangkan tulisan Universitas Wangsa Manggala disusun melingkar di luar bagian atas Kota Yogyakarta seperti berikut.

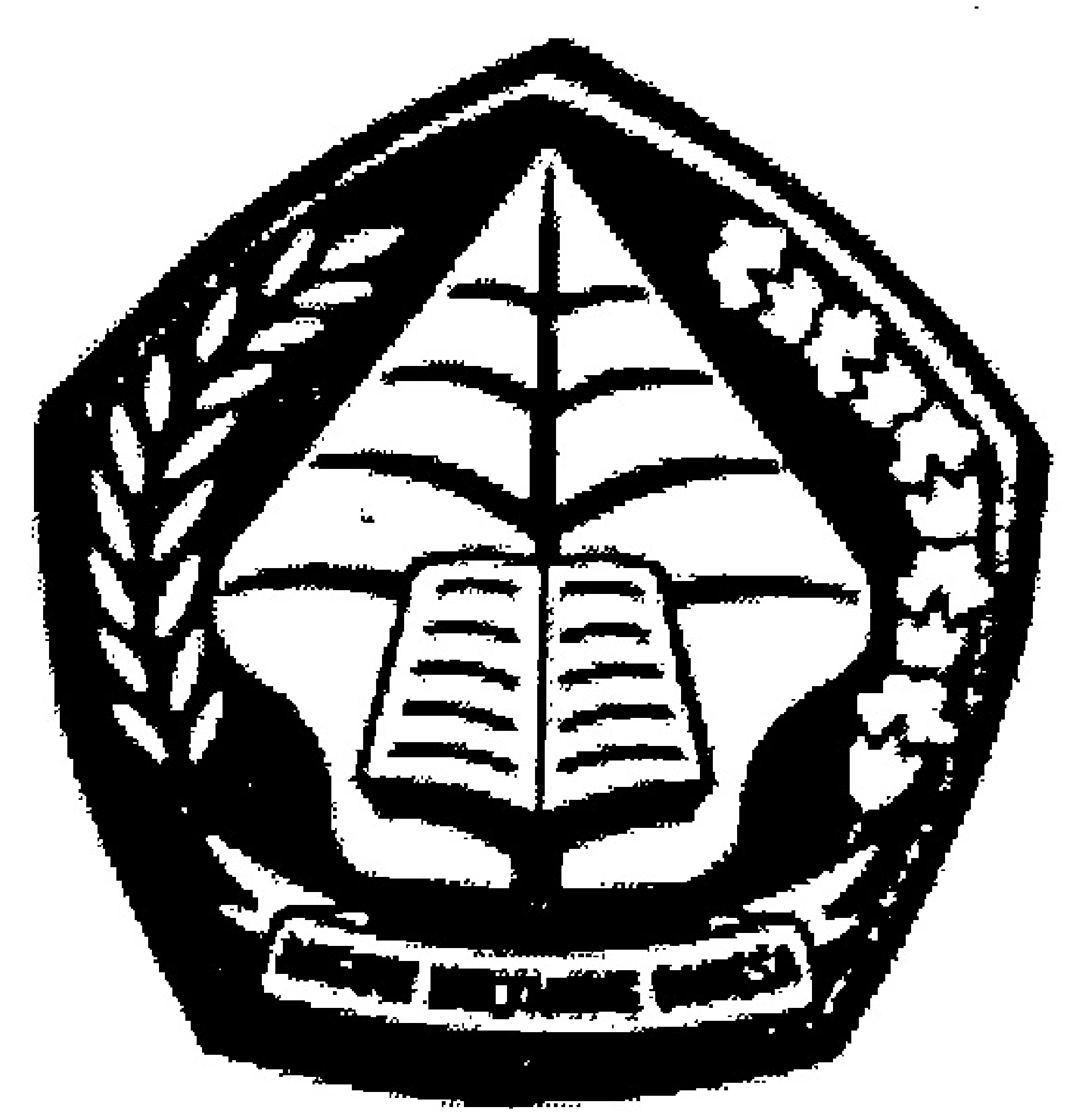

\section{Gambar 6. Lambang UNWAMA Yogyakarta}

Penerapan motif gunungan pada lambang UNWAMA Yogyakarta tampak serasi di tengah, berwarna kuning emas, terdapat gambar buku terbuka, dan bentuk seperti sirip berwarna hitam. Gunungan dan buku melambangkan ilmu pengetahuan dan teknologi yang apabila diterapkan dengan bijaksana akan dapat memberikan kesejahteraan. Dalam hal nilai-nilai gunungan wayang kulit menyatakan bahwa "manusia mempunyai kehendak untuk hidup yang baik". Hal itu sejalan dengan semboyan dalam lambang UNWAMA, "Angudi Mulyaning Bangsa", yang tertulis di bawah motif gunungan. Keadaan yang demikian menunjukkan kepada kita bahwa nilai-nilai yang terkandung di dalam motif gunungan telah menjadi satu dengan hati sanubari generasi penerusnya.

Sosialisasi lambang UNWAMA cukup gigih, dari badge yang dikenakan pada jaket almamater sampai dengan mobil dinas, papan nama, spanduk, dan buku panduan UNWAMA.

\section{Logo}

Penerapan motif gunungan pada logo terdapat pada slogan: 'Yogya Berhati Nyaman', 'Sleman Sembada', dan 'Kulonprogo Binangun'. Logo biasanya diwujudkan lebih sederhana daripada lambang, walaupun itu tidak mutlak. Logo berkesan modern, sedangkan lambang berkesan klasik. Lambang banyak menampilkan unsur-unsur yang harus mewakili suatu keadaan yang dilambangkan.

Imaji, Vol.2, No.2, Agustus 2004 : 265 - 282 
Keduanya berfungsi sebagai tanda keberadaan suatu organisasi atau daerah tertentu, sehingga akan menunjukkan identitas jati dirinya. Berikut gambar-gambar dan pembahasannya.

\section{a. Yogya Berhati Nyaman}

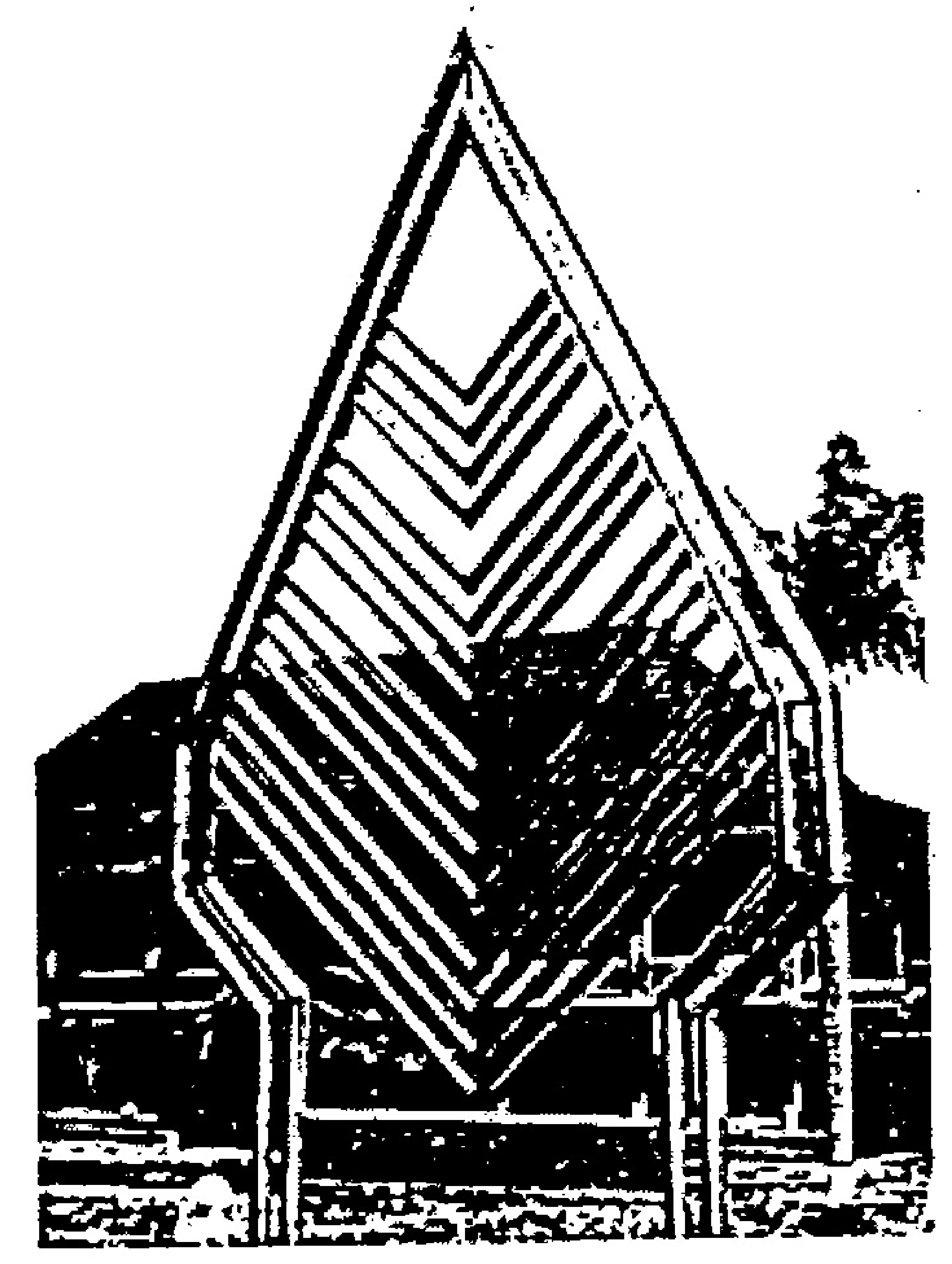

Gambar 7. Yogya Berhati Nyaman

Ditinjau dari sisi semiotika, logo "YOGYA BERHATI NYAMAN" secara global berbentuk gunungan dengan modifikasi garis lengkung menjadi irama garis patah-patah, kaku, kokoh, monumental, berkesan sederhana dan modern. Semua motif pada gunungan wayang kulit tidak dijumpai. Kesan garis-garis ritmis serba empat bermakna simbolis kota Yogyakarta berkeinginan: " bersih, sehat, indah, dan nyaman". Hal itu berawal dari falsafah budaya Ngayogyakarta Hadiningrat bah wa "perilaku yang mencerminkan tata nilai yang dilandasi Pancasila merupakan salah satu wujud kebudayaan nasional Indonesia yang harus dikembangkan dan dilestarikan". Jabaran lebih lanjut diimplementasikan pada kota Yogyakarta sebagai kota budaya, pendidikan, perjuangan, dan wisata.

Sebagaimana yang diharapakan, secara konseptual "YOGYA BERHATI NYAMAN" sebagai pedoman untuk meningkatkan tata nilai kehidupan masyarakat Yogyakarta yang mencerminkan isi dan makna Lambang Pemerintah Kota Yogyakarta. Demikian juga, itu sebagai arahan bagi seluruh aparatur dan masyarakat dalam menetapkan dan melaksanakan kebijakan pemerintah, pembangunan, dan 
kemasyarakatan. Hal yang demikian sangat relevan dengan ungkapan Sastroamidjaja (1964: 217) bahwa gunungan bermakna simbolis sebagai sumber hidup dan penghidupan, sehingga manusia akan mencapai suatu kehidupan yang adil dan makmur. Sosialisasinya dilakukan dengan dipajang di halaman kantor Pemerintah Kota Yogyakarta, perempatan jalan utama, dan taman kota yang menyatu dengan lingkungan.

\section{b. Logo Sleman Sembada}

Penerapan motif gunungan pada logo SLEMAN SEMBADA dapat dikaji dari kosep penciptaannya. Pada prinsipnya logo berbentuk segitiga sama kaki, merupakan lambang gunungan. Hal itu juga didasari oleh gunungan wayang kulit purwa. Guna menyesuaikan dengan perkembangan zaman yang senantiasa maju, logo Sleman Sembada dibuat tiga dimensional agar lebih monumental.

Ditinjau dari sisi semiotika, perancangnya telah menerapkan prinsip-prinsip desain, kesatuan, harmoni, ritme, dan keseimbangan terpadu dengan baik dan sempurna. Secara keseluruhan bentuknya berupa limas dengan alas bujur sangkar, keempat sisinya berupa segitiga sama kaki dengan proporsi alas dibanding kaki = $8: 7$. Hal itu merupakan modifikasi bentuk daun yang tertata rapi dan dilengkapi dengan "SLEMAN SEMBADA" berwarna hitam di bawahnya. Jumlah daun 12 buah yang mengandung makna simbolis 12 predikat: $S=$ sehat, $E=$ elok dan edi, $\mathrm{M}=$ makmur dan merata, $\mathrm{B}=$ berbudaya, $\mathrm{A}=$ aman dan adil, $\mathrm{D}=$ damai dan dinamis, A = agamis.

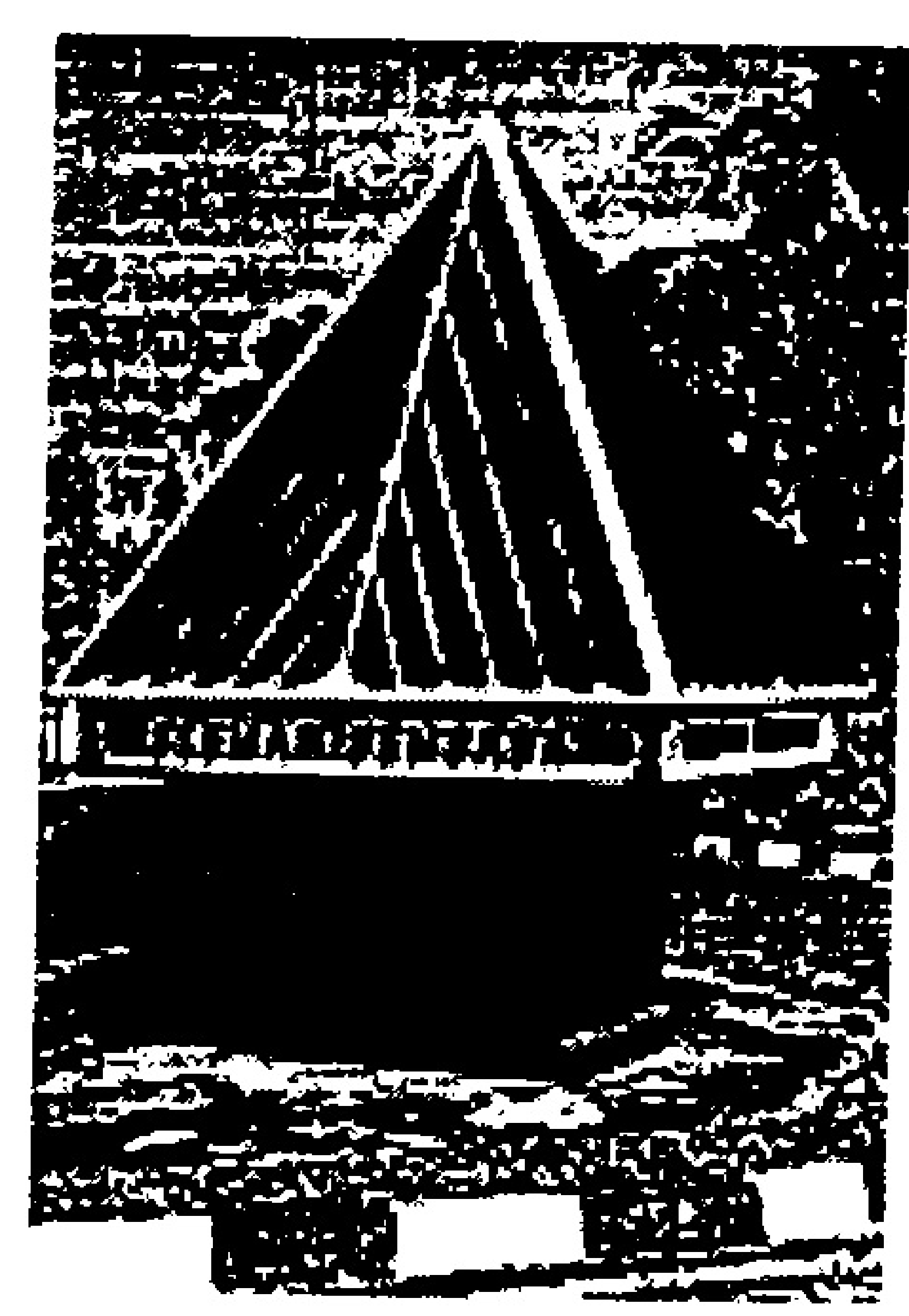

Gambar 8. Logo Sleman Sembada

Imaji, Vol.2, No.2, Agustus 2004 : 265 - 282 
Hal itu tidak meninggalkan prinsip "manunggaling kawula gusti", sehingga diharapkan cita-cita adil dan makmur cepat tercapai. Salah satu indikatornya bahwa pendapatan asli daerah (PAD) dari Pemda Sleman adalah nomor dua se-DIY setelah Kota Yogyakarta.

Dilihat secara geografis daerah Sleman merupakan lereng gunung Merapi di sisi selatan, yang secara global berbentuk segitiga sama kaki, tanahnya sangat subur untuk ditanami padi, buah-buahan, sayur-mayur, dan sangat menunjang kemakmuran rakyatnya. Hal itu juga mendasari penciptaan logo "SLEMAN SEMBADA".

Pada hakekatnya logo itu terkait dengan makna gunungan sebagai tetunggul, yang berarti paling unggul, utama, dan kuat. Dengan demikian, $\mathrm{A}=$ agamis sebagaimana yang terkandung di dalam Al Quran Surat An Nabaa: 7 yang artinya gunung-gunung sebagai pasak bumi, sehingga pulau-pulau tidak bergeser dari posisinya. Slogan tersebut diharapkan dapat memberikan motivasi kepada pemerintah dan rakyat yang seia-sekata untuk menjadi tetunggul di DIY, dengan demikian cita-cita adil dan makmur segera tercapai. Sosialisasi logo tersebut cukup bagus, yakni dibangun oleh Pemda Sleman dan masyarakat, dipasang di tempattempat yang strategis, misalnya di kantor pemerintah dan pintu-pintu jalan masuk desa, sehingga menyatu dengan alam dan lingkungannya.

\section{c. Kulon Progo Binangun}

Bentuk dasar logo 'KULON PROGO BINANGUN' adalah gunungan juga yang berbentuk segitiga sama kaki. Bentuknya sangat sederhana, gunungan dengan dasar warna kuning, terdapat sirip mirip huruf " $V$ " yang berwarna hijau muda. Sedangkan deskripsi logo 'Kulon Progo Binangun' bermakna: B: Beriman, I: Indah, N: Nuhoni, A: Aman, N: Nalar, G: Guyub, U: Ulet, dan N: Nyaman. Secara semiotik hal itu merupakan pertanda bahwa Kabupaten Kulon Progo bersemangat untuk membangun secara lahir dan batin, sesuai dengan makna kuning emas dasar gunungan yang melambangkan keluhuran, kejayaan, kebesaran, dan kewibawaan. Sedangkan, warna hijau melambangkan kesuburan, harapan keselarasan, dan ketenangan. Hal itu juga sejalan dengan makna gunungan Sekaten Yogyakarta.

Pada bagian atas logo terdapat bentuk seperti daun, yang dapat disejajarkan den gan mustika pada gunungan wayang kulit, mengandung makna karep (harapan) agar pada masa yang akan datang kita mempunyai harapan hidup yang lebi h baik. Pembuatan logo 'KULON PROGO BINANGUN' ini diprakarsai oleh Pemda Kabupaten Kulon Progo yang didukung oleh warga masyarakat secara swadaya, sehingga di setiap pelosok dusun warga masyarakat memasangnya. Hal yan $\mathrm{g}$ demikian merupakan usaha sosialisasi. Ditinjau dari sisi seni rupa hal itu merupakan upaya peningkatan apresiasi seni agar lebih memasyarakat. 


\section{Hiasan}

Penerapan motif gunungan yang dimanfaatkan untuk hiasan ada di gardu pandang Harga Dumilah Piyungan Bantul, Museum Wayang Piyungan Bantul, BPR Kallyana Adhikamandhana Gunungkidul, dan serambi masjid Agung Manunggal Bantul.

Pada gardu pandang Harga Dumilah penerapan motif gunungan berwujud sengkalan memet: " dumilahing harga trusing jagad" yang kalau dibaca dari belakang berarti tahun 1973 Masehi, tahun pembangunannya. Disayangkan sekarang bangunan itu sudah rusak dan tinggal dindingnya.

Di Museum Wayang Piyungan penerapan motif gunungan tampak pada bentuk gunungan yang megah sebagai daya tarik wisata, terletak di sisi timur gapura. Bentuknya sangat minip dengan gunungan wayang kulit purwa, begitu juga makna yang terkandung di dalamnya. Yang paling hakiki dari maknanya, sebagaimana konsep Budha, bahwa pohon merupakan sumber pengetahuan. Wayang memang pengetahuan yang sarat dengan nilai-nilai adiluhung, penuh dengan tuntunan, di samping tidak lepas sebagai tontonan.

Gunungan pada BPR Kallyana Adhikamandhana Playen Gunungkidul, sebagai hiasan di atas pintu utama sisi selatan. Secara teknis, pembuatannya dilukis sendiri oleh pemiliknya. Jika siang hari mendapat sinar dari luar, gunungan tampak sangat bagus dipandang dari dalam. Demikian halnya bila malam tiba, gunungan yang terkena sinar dari dalam akan tampak indah mempesona dipandang dari luar. Makna yang diambil oleh pemiliknya adalah: "gunungan sebagai pohon kehidupan". Terkait dengan BPR, diharapkan BPR dapat menjadi sumber kehidupan dan bermanfaat bagi masyarakat, sehingga akan membantu program pemerintah dalam mewujudkan masyarakat adil dan makmur.

Di serambi masjid Agung Manunggal Bantul, pada sisi timur terdapat hiasan berbentuk gunungan yang berfungsi sebagai pintu utama. Bentuk luar masih dekat dengan kontur gunungan wayang kulit, terdapat bentuk lubang bagian dalam lengkung ganda tapal kuda. Hal itu menunjukkan adanya pengaruh kesenian Islam Moor Afrika Utara. Namun, oleh Sunardi, arsiteknya, perpaduan tersebut lebih menyatu lagi dengan adanya lafadz Adzan dan Iqomah dengan huruf Arab Kerawangan yang mengisi bidang sisi kanan dan kiri, sehingga tampak harmonis. Keharmonisan juga tampak dari adanya hiasan pengisi bidang bawah sebelah utara yang berbentuk motif manusia sedang berdoa menengadahkan kedua tangannya. Sedangkan di bidang bawah selatan terdapat motif kitab Al Quran yang terbuka. Hal itu dimaksudkan agar manusia mau membuka Al Quran, mengerti maknanya, dan mengamalkannya. Itu tidak terlepas dari doa kepada-Nya.

Imaji, Vol.2, No.2, Agustus 2004 : 265 - 282 


\section{Monumen}

Penerapan motif gunungan pada monumen ini dapat diperhatikan pada monumen "Sendang Ayu" yang terletak di sebelah utara rumah makan lesehan Sendang Ayu. Monumen ini dibangun di atas "Belik lor" Tirto Martani, Kalasan, Sleman, Yogyakarta (sebelah utara Jl. Solo). Monumen berbentuk gunungan ini dibangun oleh Adi Kusnun dan masyarakat sekitarnya. Tujuannya sebagai rasa syukur bahwa tanaman tembakau milik Adi Kusnun dapat hidup subur karena disirami dengan air dari Sendang Ayu tersebut. Dengan demikian, panen tembakau dapat mendatangkan rejeki yang cukup banyak. Maka, sudah sewajarnyalah Adi Kusnun mensyukurinya dengan membangun monumen berbentuk gunungan tersebut.

Motif-motif yang tertera di dalamnya adalah: lar yang merupakan lambang angin, gapura (tidak dijaga oleh sepasang raksasa) lambang pintu surga, di atas gapura terdapat pohon melambangkan pohon surgawi, dililit naga yang melambangkan budi yang cendekia, tahan lapar, gemar bertapa, bersabar ketika menemui kesulitan. Hal itu sesuai dengan usaha Adi Kusnun waktu usaha menanam tembakaunya belum berhasil. Di puncak pohon terdapat banaspati dan mustika. Banaspati merupakan lambang penguasa hutan belantara, juga diartikan sebagai matahari terbit, juga mengandung makna ksatria yang sedang berjuang mencari kesempurnaan hidup. Dari sisi lain banaspati diartikan sebagai lambang waktu agar manusia senantiasa dapat memanfaatkannya sehingga tidak rugi, mengingat waktu tidak akan datang kembali.

Mustika melambangkan kehendak hidup yang baik, sebagaimana tuntunan Ilahi dalam surat Al Fatehah ihdinash shiraatal mustaqiim, 'tunjukkanlah kami, demikian pula masyarakat di sekitarnya, ke jalan yang lurus'. Di puncaknya terdapat tulisan Jawa yang merupakan surya sengkala, yang jika dibaca dari belakang berarti tahun 1993 M, tahun dibangunnya monumen berbentuk gunungan tersebut. Yang cukup menarik terdapat pula di situ tulisan Jawa berbunyi "Sendhang Ayu", nama monumen itu. Masih terdapat pula di situ surya sengkala yang lain dengan tulisan Jawa berbunyi: "wedhaning trustha arum manunggal" yang berarti tahun 1991 M, titik awal didapatkannya rejeki yang melimpah dari Allah SWT.

Dibangunnya monumen berbentuk gunungan menunjukkan adanya kesadaran masyarakat akan makna simbolis-filosofis yang mendalam bahwa gunungan sarat dengan muatan nilai-nilai luhur budaya Jawa yang patut dilestarikan dan dikembangkan sesuai dengan kemajuan zaman. Dengan demikian, gunungan tetap eksis pada masyarakat modern yang mengglobal ini. 


\section{Suvenir}

Suvenir yang berbentuk gunungan cukup banyak didapatkan di Yogyakarta, salah satu di antaranya adalah suvenir bentuk gunungan dari bahan perak Kotagede. Ukurannya cukup kecil, tinggi $12 \mathrm{~cm}$ dan lebar $5 \mathrm{~cm}$. Hal itu memang disengaja agar praktis untuk dibawa oleh pembelinya. Motif-motif yang tertera adalah sepasang raksasa, sepasang ular, harimau, banteng, pohon surga, lar, dan kemamang.

Adapun makna yang terkandung sama dengan makna motif-motif pada gunungan wayang. Yang menarik perhatian adalah terdapatnya tulisan Jawa yang berbunyi: " hanacaraka, datasawala, padajayanya, magabathanga", yang diapit oleh lar dan dikawal oleh sepasang raksasa. Tulisan ini secara semiotik merupakan tanda khusus adanya usaha untuk melestarikan huruf Jawa sebagai warisan adiluhung yang sepantasnya dilestarikan keberadaannya. Jika kita perhatikan secara keseluruhan bentuk suvenir gunungan ini memang menarik dan sangat praktis kemasannya. Gunungan suvenir ini ditempatkan pada kotak kecil yang diberi alas beludru merah hati sehingga tampak kontras dan cukup artistik. Teknik pembuatannya adalah "wudulan", ditekan-tekan dengan pahat dari sisi belakangnya.

\section{Penutup}

\section{A. Simpulan}

Penerapan motif gunungan di Daerah Istimewa Yogyakarta telah dikembangkan dan dimanfaatkan sesuai dengan berbagai macam kepentingan, misalnya untuk umum, institusi, dan pemerintah. Terkait dengan fungsinya untuk pentas, lambang, logo, hiasan, monumen, dan suvenir dapat diambil kesimpulan sebagai berikut.

1. Motif gunungan pada prinsipnya berbentuk segitiga samakaki yang mengandung makna simbolis-filosofis sebagai lambang keesaan Tuhan. Bagi masyarakat umum, institusi, dan pemerintah, gunungan dipergunakan untuk: pentas, lambang, logo, hiasan, monumen, dan suvenir, dimodifikasi seperlunya sesuai dengan kepentingan, tujuan, dan fungsinya.

2. Makna simbolis-filosofis, yakni nilai-nilai luhur yang terkandung di dalam motif gunungan Daerah Istmewa Yogyakarta, menjiwai dan mendasari kreativitas para pencipta bentuk gunungan untuk pentas, lambang, logo, hiasan, monumen, dan suvenir, sehingga tercipta bentuk-bentuk baru yang tidak meninggalkan karakternya, sesuai dengan fungsi, dan kepentingannya.

3. Implikasi dari peneraan motif gunungan yang telah dikembangkan dan dimanfaatkan untuk berbagai kepentingan di Daerah Istimewa Yogyakarta. Itu berarti masyarakat umum, akademisi, dan pemerintah sangat apresiatif dan tanggap terhadap nilai-nilai luhur yang terkandung di dalam gunungan yang sangat menjiwai kehidupan guna mencapai masyarakat yang adil dan makmur. Hal itu patut dilestarikan dan disosialisasikan agar anak-

Imaji, Vol.2, No.2, Agustus 2004 : 265 - 282 
cucu tidak buta terhadap peninggalan nenek-moyang yang adiluhung, historis, dan herois.

\section{B. Saran}

Penerapan motif gunungan di Daerah Istimewa Yogyakarta hendaknya dapat diperluas lagi sesuai dengan kepentingan dan tujuannya, misalnya logo muktamar berbagai organisasi, badan usaha milik negara, badan-badan swasta, badan sosial baru, misalnya rumah sakit, kelompok bimbingan belajar, kursus-kursus, dan masih banyak kemungkinan yang lain, sehingga lebih semarak dan lestari membumi.

\section{DAFTAR PUSTAKA}

Amidjaja, S. 1964. Renungan tentang Pertunjukan Wayang Kulit. Jakarta: PT Kinta Djakarta.

Ciptowardoyo. 1985. Wayang sebagai Media Pendidikan Ditinjau dari Makna dan Filosofinya. Yogyakarta: Kanisius.

Hoop, van D. 1975. Ragam-Ragam Perhiasan Indonesia. Jakarta: Pemda DKI Jakarta.

Moertjipto dan Prasetyo. 1992. Candi Prambanan. Yogyakarta: Kanisius.

Moleong, J. L. 2000. Metodologi Penelitian Kualitatif. Bandung: PT Remaja Rosda Karya.

Sunaryo, Edi. 1997. Wujud dan Makna Perlambang Gunungan Garebeg dalam Budaya Keraton Yogyakarta. Bandung: ITB.

TIM. 2000. Selayang Pandang Kota Yogyakarta. Yogyakarta: Humas Kota Yogyakarta.

1992. Lembaran Daerah Kabupaten Sleman. Sleman: Pemda Sleman. 2001. Informasi Singkat tentang Universitas Wangsa Manggala Yogyakarta. Yogyakarta: Humas Unwama.

Utami, Sri, dkk. 2000. Petunjuk Koleksi Monumen Yogya Kembali. Yogyakarta: Badan Pengelola Monjali.

Nara Sumber

Penerapan Motif Gunungan di Daerah Istimewa Yogyakarta (Suwarna) 